University of Nebraska - Lincoln

DigitalCommons@University of Nebraska - Lincoln

\title{
AUTOMATED DETECTION OF SINGLE WHEAT KERNELS CONTAINING LIVE OR DEAD INSECTS USING NEAR-INFRARED REFLECTANCE SPECTROSCOPY
}

\author{
Elizabeth B. Maghirang \\ Kansas State University, emaghira@gmprc.ksu.edu \\ F. E. Dowell \\ USDA-ARS \\ J. E. Baker \\ USDA-ARS \\ James E. Throne \\ USDA-ARS, Manhattan, KS, james.throne@ars.usda.gov
}

Follow this and additional works at: https://digitalcommons.unl.edu/usdaarsfacpub

Maghirang, Elizabeth B.; Dowell, F. E.; Baker, J. E.; and Throne, James E., "AUTOMATED DETECTION OF SINGLE WHEAT KERNELS CONTAINING LIVE OR DEAD INSECTS USING NEAR-INFRARED REFLECTANCE SPECTROSCOPY" (2003). Publications from USDA-ARS / UNL Faculty. 2067.

https://digitalcommons.unl.edu/usdaarsfacpub/2067

This Article is brought to you for free and open access by the U.S. Department of Agriculture: Agricultural Research Service, Lincoln, Nebraska at DigitalCommons@University of Nebraska - Lincoln. It has been accepted for inclusion in Publications from USDA-ARS / UNL Faculty by an authorized administrator of DigitalCommons@University of Nebraska - Lincoln. 


\title{
Automated Detection of Single Wheat Kernels CONTAINING Live or DeAD InSECTS USing NeAR-Infrared Reflectance Spectroscopy
}

\author{
E. B. Maghirang, F. E. Dowell, J. E. Baker, J. E. Throne
}

\begin{abstract}
An automated near-infrared (NIR) reflectance system was used over a two-month storage period to detect single wheat kernels that contained live or dead internal rice weevils at various stages of growth. Correct classification of sound kernels plus kernels containing live pupae, large larvae, medium-sized larvae, and small larvae averaged 94\%, 93\%, 84\%, and $63 \%$, respectively. Pupae + large larvae calibrations were developed for live (day 1) and dead (days 7, 14, 28, 42, and 56) internal insects. Validation results showed that the live pupae +live large larvae calibration correctly classified $86 \%$ to $96 \%$ of dead pupae + dead large larvae validation samples. The dead pupae + dead large larvae calibration correctly detected the presence of live pupae + live large larvae with an accuracy of $92 \%$ to $93 \%$. Thus, wheat kernels containing either live or dead insects can be used to develop calibrations for detecting both live and dead insects in wheat. These findings will impact how calibration sample sets can be handled. Results indicated that immediate sample processing for creating calibrations may no longer be necessary; internal insects can be killed and calibrations created at a later time without sacrificing accuracy. Additionally, laboratories can share these same calibration samples to save time and resources.
\end{abstract}

Keywords. Grading, Hidden insects, Inspection, Internal insects, Rice weevil, Single kernel, Single kernel characteristics, Wheat quality.

$\mathrm{R}$ ice weevil (Sitophilus oryzae L.) is a primary pest of hard red winter wheat (Triticum aestivum L.). Adult insects feed on the kernel surface but deposit eggs inside kernels. Weevil larvae feed and complete development inside the kernel until they mature and emerge as adults. The presence of internal insects in wheat is a major problem for the wheat industry. The insects may eventually emerge and cause further damage to kernels and contribute to fragments in flour. While a wheat lot may visually appear to be sound or uninfested, internal insects may be present in some kernels. The presence of live or dead internal insects in wheat kernels equates to lower wheat quality. In the U.S., the Food and Drug Administration (FDA) has imposed the defect action level for insect contamination to be 32 or more insect damaged kernels per $100 \mathrm{~g}$ of wheat and 75 or more insect fragments per $50 \mathrm{~g}$ of flour (FDA, 1998). To coincide with the FDA's defect action levels, the U.S. standards for wheat consider wheat containing 32 or

Article was submitted for review in October 2002; approved for publication by the Information \& Electrical Technologies Division of ASAE in April 2003. Presented at the 2002 ASAE Annual Meeting as Paper No. 023067. Kansas Agricultural Experiment Station Contribution No. 02-401-A.

The authors are Elizabeth B. Maghirang, ASAE Member Engineer, Agricultural Engineer, and Floyd E. Dowell, ASAE Member Engineer, Agricultural Engineer, USDA-ARS Grain Marketing and Production Research Center (GMPRC) Engineering Research Unit, Manhattan, Kansas; and James E. Baker, Entomologist, and James E. Throne, Entomologist, USDA-ARS GMPRC Biological Research Unit, Manhattan, Kansas. Corresponding author: Elizabeth B. Maghirang, USDA-ARS GMPRC Engineering Research Unit, 1515 College Avenue, Manhattan, KS 66502; phone: 785-776-2730; fax: 785-537-5550; e-mail: emaghira@gmprc.ksu.edu. more insect-damaged kernels per $100 \mathrm{~g}$ as U.S. sample grade. Those containing less than 32 insect-damaged kernels can be given a designation of U.S. grades 1 to 5 based on other set criteria; it may be certified with a special grade of "infested" based on the presence of live weevils or other live insects injurious to stored grains (USDA, 1997).

Numerous studies have focused on the development of methods for detecting internal insects, which are needed because visual inspection cannot effectively detect internal insects. For example, visual inspection showed that $4 \%$ of wheat samples from 79 U.S. grain elevators were infested with insects, while incubation of the same wheat samples over 3 to 6 weeks showed $16 \%$ insect infestation (Storey et al., 1982). Other detection techniques include: (a) selective fluorescent stains (Milner et al., 1950a), (b) x-ray inspection (Milner et al., 1950b; Schatzki and Fine, 1988; Keagy and Schatzki, 1993; Throne, 1994; AACC, 2001; Haff, 2001), (c) cracking and flotation (AACC, 2001), (d) acid hydrolysis test (Trauba et al., 1981; AACC, 2001), (e) immunological technique (Kitto, 1991; Quinn et al., 1992; Schatzki et al., 1993), (f) machine vision (Zayas and Flinn, 1998; Ridgway et al., 2001), (g) acoustic and acousto-fluidic detection methods (Shuman et al., 1993; Mankin et al., 1997; Chesmore and Nellenbach, 2001; Drzewiecki and Shuman, 2001), and (h) near-infrared (NIR) spectroscopy (Chambers and Ridgway, 1996; Ridgway and Chambers, 1996, 1998; Ghaedian and Wehling, 1997; Dowell et al., 1998, 1999; Baker et al., 1998; Ridgway et al., 1999; Cheewapramong and Wehling, 2001; Ridgway et al., 2001). Pedersen (1992) and Brader et al. (2002) reviewed some of these screening methods for insect contamination in wheat.

NIR spectroscopy has the advantage of being a rapid and accurate method that can be adapted for non-destructive and 
automated detection. Previous studies show that live (e.g., Dowell et al., 1998; Ridgway and Chambers, 1999) and dead internal insects (e.g., Cheewapramong and Wehling, 2001) can be detected using NIR. The current study builds further on the potential of using NIR for detecting single kernels of wheat containing dead or desiccated insects. Considering that several NIR instruments capable of handling single kernels are already being used for measuring other quality attributes, adding the capability to detect kernels containing live and dead internal insects automatically and non-destructively will be highly beneficial. In addition, no published research has validated whether calibrations developed using wheat kernels containing either live or dead internal insects can be used to detect kernels containing live and dead insects over a storage period. The objectives of this research were:

- To evaluate the potential of a commercially available automated NIR system for detecting wheat kernels containing live and dead internal insects (rice weevil) at varying stages of growth in wheat stored over a two-month period.

- To determine and validate whether calibrations using wheat samples containing either live or dead internal insects can be used to predict the presence of both live and dead internal insects in single wheat kernels.

\section{Methodology \\ Wheat SAMPLe}

About $1 \mathrm{~kg}$ commercial hard red winter wheat sample obtained from the 2001 Kansas harvest was adjusted to $13.5 \%$ moisture content (wet basis) by addition of a pre-determined amount of water. After a 7-day equilibration period, adult weevils were allowed to oviposit into the wheat for 10 days, after which the weevils were removed by screening. After 21 days at $27^{\circ} \mathrm{C}$ and $55 \%$ to $60 \%$ relative humidity, a portion of randomly picked wheat kernels were $\mathrm{x}$-rayed following the procedure outlined by Throne (1994) to obtain:

(a) 200 uninfested or sound kernels - free of internal insects,

(b) 100 kernels containing pupae - pronounced or visible limbs, snout, and/or wings,

(c) 100 kernels containing large larvae - fourth larval instar stage,

(d) 100 kernels containing medium-sized larvae second or third larval instar stage, and

(e) 100 kernels containing small larvae - first or second larval instar stage.

All infested kernels selected contained one internal insect per kernel.

After the spectra of wheat kernels were obtained (see below), 100 sound kernels were set aside, while the remaining samples were treated with phosphine to kill the internal insects. Phosphine treatment involved placing each set of samples in separate labeled jars that were positioned in a dessicator together with $100 \mathrm{mg}$ shavings of a commercially available aluminum phosphide (Phostoxin tablet, Degesch America, Inc., Weyers Cave, Va.). Fumigation in the dessicator was done in a fume hood for 3 days. After fumigation, the samples were placed in individual compartments of labeled pillboxes and allowed to equilibrate under ambient room conditions $\left(18^{\circ} \mathrm{C}\right.$ to $21^{\circ} \mathrm{C}$ and about $35 \%$ to
$40 \%$ relative humidity) for 4 days prior to the next spectra collection. All samples were stored under these conditions between all tests.

\section{InSTRUMENTATION AND SPECTRA MEASUREMENT}

The Single Kernel Characterization System (SKCS) 4170 (Perten Instruments, Springfield, Ill.) was used for automated and singulated collection of the spectra of individual wheat kernels. As described by Dowell et al. (1998), the SKCS4170 integrates the diode-array near-infrared spectrometer with the SKCS 4100. The system automatically delivered and randomly positioned a single kernel in a kernel bucket, which is the spectrometer viewing area. Eight spectra were collected for each kernel at 400 to $1700 \mathrm{~nm}$, averaged to reduce noise, and recorded in $5 \mathrm{~nm}$ increments. The kernel was then dropped out of the kernel bucket, and the next kernel was automatically delivered to the viewing area. Kernels were delivered at a rate of 1 kernel per 4 seconds. The spectra were stored on a hard disk for subsequent analysis.

Six sets of spectral data were collected for samples from days $1,7,14,28,42$, and 56 to establish the potential of model development using the same sample at different time periods. The first set, referred to as the day 1 sample, was obtained immediately after the samples were $\mathrm{x}$-rayed and sorted. Day 1 samples included sound and infested kernels containing live rice weevils at various stages of growth. Day 7, 14, 28,42 , and 56 samples included wheat kernels that were untreated sound, phosphine-treated sound, and phosphinetreated containing rice weevils at various stages of growth that had been stored for 7, 14, 28, 42, or 56 days, respectively. The wheat kernels scanned on day 1 were the same wheat kernels scanned on days 7 to 56 .

\section{Data AnAlysis}

Spectra were analyzed by partial least squares (PLS) regression, a spectral decomposition technique similar to principal component regression (Martens and Naes, 1989) using PLSPlus/IQ software (Galactic Industries, Salem, N.H.). Sound kernels were assigned a score of 1 and kernels with internal rice weevils were assigned a score of 2. Galactic Industries (2003) provided the algorithm describing how PLSPlus/IQ took advantage of the correlation relationship that existed between the spectral data and the constituent concentrations. The spectral decomposition generated two sets of vectors and two sets of corresponding scores: one set for the spectral data, and the other for the constituent concentrations. Based on the relationship of the two sets of scores through regression, a calibration model was constructed.

The coefficient of determination $\left(\mathrm{r}^{2}\right)$, standard error of cross validation (SECV), beta coefficient, and percentage of correct classification were used to evaluate the potential of the NIR technique. The SECV was used to determine the "best" number of independent variables in building a calibration equation. Beta coefficients indicated the wavelengths (positive and negative peaks in the plot) that are more heavily weighted. The percentage classification accuracy referred to the combined sound and infested kernels that were correctly classified divided by the total number of sound and infested kernels. Considering that no spectral difference was found between fumigated and not fumigated sound kernels over time, the fumigated sound kernels were used to 
represent sound kernels. Cross-validation, which attempts to emulate predicting "unknown" samples by using the training data set itself (Galactic Industries, Salem, N.H.), was used to determine classification accuracy within a spectral data set. The optimum number of factors used for the model was determined by combined examination of the prediction residual error sum of squares (PRESS) plot, $\mathrm{r}^{2}, \mathrm{SECV}$, and beta coefficient plot, which were all generated by the PLSPlus/IQ software.

Dowell et al. (1998) showed that the visible or very near infrared regions do not contribute to the classification information for detecting internal insects in wheat. Thus, calibrations were developed in the 950 to $1690 \mathrm{~nm}$ wavelength range for: (a) pupae, (b) large larvae, (c) mediumsized larvae, (d) small larvae, (e) pupae + large larvae + medium-sized larvae + small larvae, (f) pupae + large larvae + medium-sized larvae, (g) and pupae + large larvae models. Based on statistical measures, a calibration model for each spectral data set was chosen.

The selected calibration model for each of the spectral data sets was validated against the other spectral data sets. For example, the day 1 calibration was used to validate classification accuracy of the same set of samples with spectral data collected on days $7,14,28,42$, and 56; day 56 calibration was used to validate classification accuracy for days $1,7,14,28$, and 42 . Validation involved use of the calibration model to predict whether a kernel was sound (score $=1)$ or infested (score $=2$ ). Based on the prediction results, the percentage classification accuracy of the calibration model was then determined.

\section{Results AND Discussion}

Figures $1 \mathrm{a}$ and $1 \mathrm{~b}$ show the absorbance (logarithm of the inverse of reflectance, $\log 1 / \mathrm{R})$ of the average of 50 kernels of sound (uninfested) and infested wheat kernels (pupae, large larvae, medium-sized larvae, and small larvae) for days 1 and 56, respectively. Day 1 samples contain live internal rice weevils, while day 56 samples contain dead internal rice weevils that were stored for 56 days after being killed with phosphine treatment. The standard deviation in absorbance for sound and infested single wheat kernels for the entire wavelength ranged from 0.01 to 0.24 , indicating the degree of overlap between infestation levels. Spectra of wheat samples containing dead rice weevils at days 7, 14, 28, and 42 (spectra not shown) had the same trends as those for days 1 and 56. Absorbance was generally highest for sound wheat kernels and decreased at later growth stages. These results agreed with results of Dowell et al. (1998) and Ridgway et al. (1999) for live internal insects.

Figure 2 provides PLS beta coefficient output for three representative sampling times (days 1, 28, and 56) at the optimum number of PLS factors. Beta coefficient positive and negative peaks for days 7, 14, and 42 (beta coefficients not shown) were the same as those for days 1,28 , and 56 . Important wavelengths for detecting the presence of internal insects in wheat kernels (across live or dead internal insects and across storage periods) indicated by the beta coefficients generally occurred around 990, 1135, 1210, 1325, 1370, 1395, 1425, 1510, 1610, and $1670 \mathrm{~nm}$. The $990 \mathrm{~nm}$ negative peak, which corresponds to starch, agrees with the findings of Ridgway et al. (1999), indicating that the ability to detect
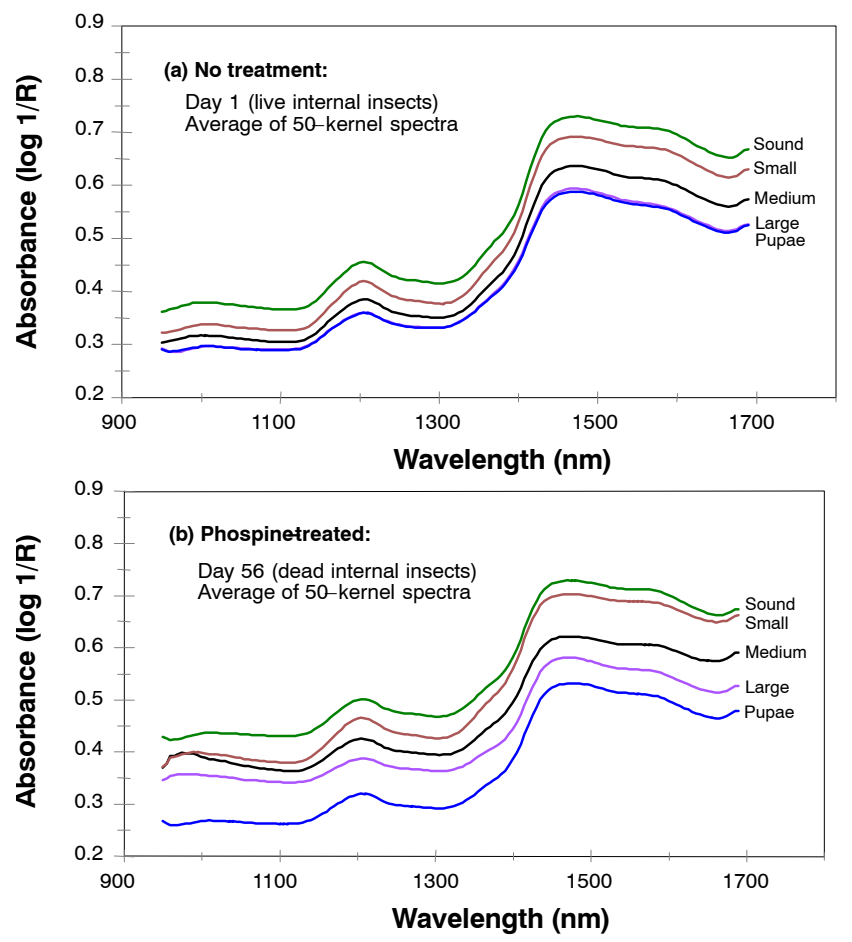

Figure 1. Comparison of reflectance spectra of wheat kernels that are sound or internally infested by (a) live or (b) dead internal rice weevils at various stages of growth. Day 56 spectra were used to represent kernels containing dead internal insect (similar trends were found for days 7,14 , 21, 28, and 42). Each plot represents the average spectra of 50 single wheat kernels.

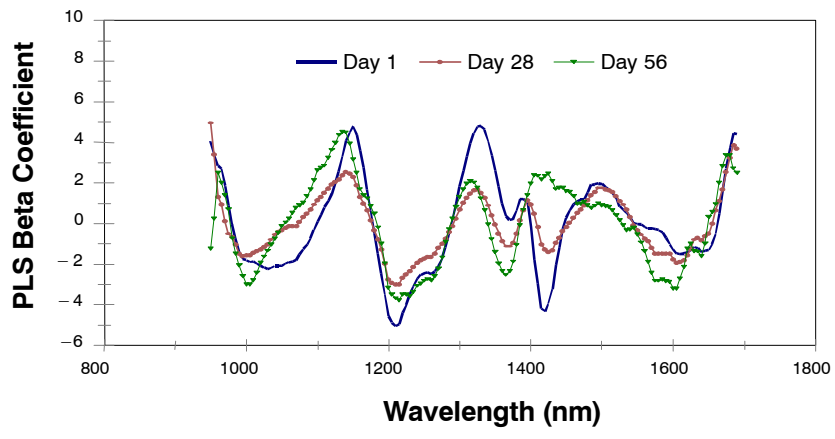

Figure 2. Partial least squares regression beta coefficients (days 1, 28, and 56 samples) used for indicating important NIR wavelengths for detecting kernels containing internal rice weevils (number of factors $=6$ ).

wheat kernels containing insects may be due to the loss of starch from the kernel that was replaced and/or consumed by the developing larvae. The wavelength region around $1425 \mathrm{~nm}$ was also identified by Ridgway and Chambers (1996) and is likely a response to insect moisture. The 1510 wavelength corresponding to the nitrogen-hydrogen $(\mathrm{N}-\mathrm{H})$ stretch 1st overtone bond vibration indicated that the ability to detect wheat kernels with internal insect may partly be attributed to the change in protein content of the wheat kernel.

The other regions correspond to carbon (C), $\mathrm{H}$ 1st and 2nd overtones, and $\mathrm{C}-\mathrm{H}$ combination bond vibrations (Shenk et al., 1992). Absorption in the $\mathrm{C}-\mathrm{H}$ region may be attributed to the presence of rice weevil cuticular lipids, which Dowell et al. (1999) reported had peaks at 1130 and $1670 \mathrm{~nm}$. The data provide evidence that the physical or biochemical differ- 
Table 1. Summary of performance of calibration models developed for detecting wheat kernels that are sound or infested by rice weevil.

\begin{tabular}{|c|c|c|c|c|}
\hline Calibration Model & $\begin{array}{l}\text { No. of } \\
\text { Factors }\end{array}$ & $r^{2}$ & SECV & $\begin{array}{l}\mathrm{CC} \\
(\%)\end{array}$ \\
\hline \multicolumn{5}{|l|}{ Day 1 (Live) } \\
\hline Pupae & 7 & 0.73 & 0.21 & 94 \\
\hline Large larvae & 7 & 0.74 & 0.25 & 95 \\
\hline Medium-sized larvae & 6 & 0.40 & 0.39 & 84 \\
\hline Small larvae & 6 & 0.22 & 0.44 & 71 \\
\hline Pupae + large larvae (PL1) & 6 & 0.71 & 0.27 & 93 \\
\hline Pupae + large + medium larvae & 6 & 0.44 & 0.35 & 87 \\
\hline $\begin{array}{l}\text { Pupae }+ \text { large }+ \text { medium }+ \\
\text { small larvae }\end{array}$ & 6 & 0.22 & 0.38 & 78 \\
\hline \multicolumn{5}{|l|}{ Day 7 (Dead) } \\
\hline Pupae & 7 & 0.78 & 0.23 & 93 \\
\hline Large larvae & 7 & 0.76 & 0.25 & 93 \\
\hline Medium-sized larvae & 6 & 0.52 & 0.35 & 88 \\
\hline Small larvae & 5 & 0.02 & 0.50 & 68 \\
\hline Pupae + large larvae (PL7) & 7 & 0.71 & 0.25 & 95 \\
\hline Pupae + large + medium larvae & 8 & 0.54 & 0.29 & 92 \\
\hline $\begin{array}{l}\text { Pupae }+ \text { large }+ \text { medium }+ \\
\text { small larvae }\end{array}$ & 5 & 0.22 & 0.35 & 80 \\
\hline \multicolumn{5}{|l|}{ Day 14 (Dead) } \\
\hline Pupae & 6 & 0.78 & 0.23 & 95 \\
\hline Large larvae & 6 & 0.73 & 0.26 & 93 \\
\hline Medium-sized larvae & 6 & 0.48 & 0.36 & 86 \\
\hline Small larvae & 6 & 0.08 & 0.49 & 62 \\
\hline Pupae + large larvae (PL14) & 6 & 0.72 & 0.25 & 96 \\
\hline Pupae + large + medium larvae & 6 & 0.51 & 0.30 & 92 \\
\hline $\begin{array}{l}\text { Pupae }+ \text { large }+ \text { medium }+ \\
\text { small larvae }\end{array}$ & 6 & 0.25 & 0.35 & 81 \\
\hline \multicolumn{5}{|l|}{ Day 28 (Dead) } \\
\hline Pupae & 6 & 0.72 & 0.27 & 94 \\
\hline Large larvae & 6 & 0.65 & 0.30 & 92 \\
\hline Medium-sized larvae & 6 & 0.50 & 0.36 & 86 \\
\hline Small larvae & 6 & 0.08 & 0.48 & 62 \\
\hline Pupae + large larvae (PL28) & 6 & 0.65 & 0.28 & 93 \\
\hline Pupae + large + medium larvae & 9 & 0.54 & 0.30 & 92 \\
\hline $\begin{array}{l}\text { Pupae }+ \text { large }+ \text { medium }+ \\
\text { small larvae }\end{array}$ & 9 & 0.30 & 0.34 & 80 \\
\hline \multicolumn{5}{|l|}{ Day 42 (Dead) } \\
\hline Pupae & 5 & 0.76 & 0.24 & 95 \\
\hline Large larvae & 6 & 0.63 & 0.30 & 90 \\
\hline Medium-sized larvae & 5 & 0.38 & 0.40 & 80 \\
\hline Small larvae & 3 & 0.03 & 0.50 & 57 \\
\hline Pupae + large larvae (PL42) & 5 & 0.66 & 0.28 & 91 \\
\hline Pupae + large + medium larvae & 5 & 0.43 & 0.33 & 89 \\
\hline $\begin{array}{l}\text { Pupae }+ \text { large }+ \text { medium }+ \\
\text { small larvae }\end{array}$ & 3 & 0.21 & 0.36 & 80 \\
\hline \multicolumn{5}{|l|}{ Day 56 (Dead) } \\
\hline Pupae & 6 & 0.74 & 0.26 & 95 \\
\hline Large larvae & 6 & 0.67 & 0.29 & 92 \\
\hline Medium-sized larvae & 6 & 0.43 & 0.38 & 82 \\
\hline Small larvae & 2 & 0.04 & 0.49 & 56 \\
\hline Pupae + large larvae (PL56) & 6 & 0.67 & 0.28 & 91 \\
\hline Pupae + large + medium larvae & 6 & 0.47 & 0.32 & 89 \\
\hline $\begin{array}{l}\text { Pupae }+ \text { large }+ \text { medium }+ \\
\text { small larvae }\end{array}$ & 3 & 0.22 & 0.36 & 82 \\
\hline $\begin{array}{ll}\mathrm{r}^{2} & =\text { coefficient of determinat } \\
\mathrm{SECV} & =\text { standard error of cross } \mathrm{v} \\
\mathrm{CC} & =\text { correct classification }\end{array}$ & n. & & & \\
\hline
\end{tabular}

ences detected by NIR for live insects are generally the same factors detected by NIR for dead insects over a two-month storage period.
Table 2. Correct classification of wheat samples validated using a calibration developed from pupae + large larvae.

\begin{tabular}{lcccccc}
\hline & \multicolumn{5}{c}{$\begin{array}{c}\text { Percentage of Correct Classification } \\
\text { for Validation Sample }\end{array}$} \\
\cline { 2 - 7 } Calibration & Live, & \multicolumn{5}{c}{ Dead } \\
\cline { 2 - 7 } Model & Day 1 & Day 7 & Day 14 & Day 28 & Day 42 & Day 56 \\
\hline Day 1 (live) & - & 89.8 & 94.5 & 87.2 & 88.6 & 86.5 \\
Day 7 (dead) & 93.3 & - & 95.5 & 89.1 & 90.0 & 88.3 \\
Day 14 (dead) & 93.0 & 93.7 & - & 92.6 & 91.8 & 92.2 \\
Day 28 (dead) & 91.7 & 93.0 & 92.1 & - & 91.2 & 90.0 \\
Day 42 (dead) & 93.0 & 90.9 & 91.8 & 91.2 & - & 90.0 \\
Day 56 (dead) & 91.7 & 86.3 & 93.2 & 89.1 & 92.9 & - \\
\hline
\end{tabular}

\section{Model Calibration}

Table 1 lists the calibration models developed and corresponding cross-validation results for differentiating sound versus infested kernels. Wheat samples containing pupae or large larvae were correctly classified against sound kernels with greater than $90 \%$ accuracy, and the models had $\mathrm{r}^{2}$ values ranging from 0.63 to 0.78 . Samples containing medium larvae had $\mathrm{r}^{2}$ values ranging from 0.38 to 0.52 and correct classification (CC) ranging from $80 \%$ to $88 \%$. Samples containing small larvae were not well differentiated from sound kernels; $\mathrm{r}^{2}$ values ranged from only 0.02 to 0.22 , and $\mathrm{CC}$ ranged from $56 \%$ to $71 \%$. Thus, wheat kernels containing small larvae were not included in the final calibration model.

The pupae + large larvae + medium-sized larvae had CC values that ranged from $87 \%$ to $92 \%$, SECV values of 0.29 to 0.35 , and $\mathrm{r}^{2}$ values of 0.43 to 0.54 . The pupae + large larvae model had $\mathrm{r}^{2}$ values ranging from 0.65 to $0.72, \mathrm{CC}$ values of $91 \%$ to $96 \%$, and SECV values of 0.25 to 0.28 . Based on these parameters, samples containing medium larvae were also not included in the final calibration model. The pupae + large larvae model was developed as the final calibration model for all six spectral data sets. The current calibration models are thus limited by their ability to predict the presence of pupae and large larvae only. However, considering that a wheat lot would likely have many different stages of internal insects at a given time, the model's ability to detect pupae and large larvae will be able to provide critical information for determining whether a wheat lot is infested.

\section{Model VAlidation}

Each of the spectral data sets of the pupae + large larvae model was validated against the other five pupae + large larvae spectral data sets that were obtained at different storage times. Table 2 summarizes the percentage of $\mathrm{CC}$ for each validation model. When the calibration developed using live (day 1) pupae + large larvae was used to detect dead (days 7 to 56) pupae + large larvae, the $\mathrm{CC}$ values ranged from $86 \%$ to $96 \%$. Calibrations that used dead (days 7 to 56) pupae + large larvae detected the presence of live (day 1) pupae + large larvae with $\mathrm{CC}$ values ranging from $92 \%$ to $93 \%$.

These results proved that the pupae + large larvae calibration, regardless of whether the reference samples contained dead or live rice weevils, effectively ( $86 \%$ to $96 \%$ ) detected the presence of either live or dead internal rice weevils in wheat samples. Additionally, this detection performance was achieved using an automated single-kernel NIR system. 


\section{ConClusion}

The SKCS 4170, an automated single-kernel NIR system, detected the kernels containing either live or dead rice weevils in single hard red winter wheat kernels during a two-month storage period. Correct classification of sound kernels and kernels containing live insects at pupal, large, medium-sized, and small larval stages averaged 94\%, 93\%, $84 \%$, and $62 \%$, respectively.

The best calibration models for each sample set containing live (day 1) and dead (days 7, 14, 28, 42, and 56) rice weevils were obtained using the pupae + large larvae samples. Validation results showed correct classifications ranging from $86 \%$ to $96 \%$ over the two-month storage period. The live pupae + large larvae (day 1) calibration yielded an $86 \%$ to $96 \%$ correct classification for dead pupae + large larvae validation samples. Calibrations that used dead pupae + large larvae over a two-month storage period correctly detected the presence of live pupae + large larvae with an accuracy of $92 \%$ to $93 \%$.

These results indicate that calibrations can be developed using wheat samples containing either live or dead internal insects. These findings impact how calibration sample sets can be handled. Results showed that immediate sample processing for creation of calibrations may no longer be necessary; internal insects can be killed and calibrations can be created at a later time without sacrificing accuracy. There will be considerable savings in time and resources required for preparing calibration or reference samples. Additionally, calibration samples can be shared across locations or laboratories without sacrificing classification accuracies.

\section{ACKNOWLEDGEMENTS}

The authors would like to acknowledge Duane Walker for his instrumentation expertise and Dan Brabec and Ann Redmon for providing technical assistance for phosphine treatment, $\mathrm{x}$-ray work, and sample classification.

\section{REFERENCES}

AACC Standards. 2001. Method 28-21: X-ray method; Methods 28-22 and 28-51: Cracking and flotation method; Method 28-41A: Acid hydrolysis test. St. Paul, Minn.: AACC.

Baker, J. E., F. E. Dowell, and J. E. Throne. 1998. Detection of parasitized rice weevils in wheat kernels with near-infrared spectroscopy. Biological Control 16(1): 88-90.

Brader, B., R. C. Lee, R. Plarre, W. Burkholder, G. B. Kitto, C. Kao, L. Polston, E. Dorneanu, I. Szabo, B. Mead, B. Rouse, D. Sullins, and R. Denning. 2002. A comparison of screening methods for insect contamination in wheat. J. Stored Prod. Research 38(1): 75-86.

Chambers, J., and C. Ridgway. 1996. Rapid detection of contaminants in cereals. In Near-Infrared Spectroscopy: The New Waves, 484-489. A. M. C. Davies and P. Williams, eds. Chichester, U.K.: NIR Publications.

Cheewapramong, P., and R. L. Wehling. 2001. A simplified near-infrared method for detecting internal insect infestation in wheat kernels. AACC Abstract Paper 368. St. Paul, Minn.: AACC.

Chesmore, E. D., and C. Nellenbach. 2001. Acoustic methods for the automated detection and identification of insects. Acta Hort. (ISHS) 562: 223-231. Available at: www.actahort.org/books/562/562_26.htm. Accessed on 13 March 2003.
Dowell, F. E., J. E. Throne, and J. E. Baker. 1998. Automated nondestructive detection of internal insect infestation of wheat kernels by using near-infrared reflectance spectroscopy. J. Econ. Entomology 91(4): 899-904.

Dowell, F. E., J. E. Throne, D. Wang, and J. E. Baker. 1999. Identifying stored-grain insects using near-infrared spectroscopy. J. Econ. Entomology 92(1): 165-169.

Drzewiecki, T. M., and D. Shuman. 2001. Acousto-fluidic detection of insect larvae in grain. Acta Hort. (ISHS) 562: 233-241. Available at: www.actahort.org/books/ 562/562_27.htm. Accessed on 13 March 2003.

FDA. 1998. Defect action level handbook. Washington, D.C.: Food and Drug Administration, Center for Safety and Nutrition. Available at: http://vm.cfsan.fda.gov/ dms/dalbook.html. Accessed on 12 March 2002.

Galactic Industries. 2003. Algorithms: Partial least squares. Available at: www.galactic.com/algorithms/pls.htm. Accessed on 13 March 2003.

Ghaedian, A. R., and R. L. Wehling. 1997. Discrimination of sound and granary-weevil-larva-infested wheat kernels by near-infrared diffuse reflectance spectroscopy. J. AOAC Intl. 80(5): 997-1005.

Haff, R. P. 2001. X-ray inspection of wheat for granary weevils. PhD diss. Davis, Cal.: University of California.

Keagy, P. M., and T. F. Schatzki. 1993. Machine recognition of weevil damage in wheat radiograms. Cereal Chemistry 70(6): 696-700.

Kitto, G. B. 1991. A new rapid biochemical technique for quantitating insect contamination in grain. Assoc. Operative Millers Tech. Bulletin (March): 5835-5838.

Mankin, R. W., D. Shuman, and J. A. Coffelt. 1997. Acoustic counting of adult insects with differing rates and intensities of sound production in stored wheat. J. Econ. Entomology 90(4): 1032-1038.

Martens, H., and T. Naes. 1989. Multivariate Calibration. Chichester, U.K.: John Wiley and Sons.

Milner, M., D. L. Barney, and J. A. Shellenberger. 1950a. Use of selective fluorescent stains to detect insect egg plugs on grain kernels. Science 112: 791-792.

Milner, M., M. R. Lee, and R. Katz. 1950b. Application of x-ray technique to the detection of internal insect infestation of grain. J. Econ. Entomology 43(6): 933-935.

Pedersen, J. R. 1992. Insects: Identification, damage, and detection. In Storage of Cereal Grains and Their Products, 435-489. D. B. Sauer, ed. St. Paul, Minn.: AACC.

Quinn, F. A., W. Burkholder, and G. B. Kitto. 1992. Immunological technique for measuring insect contamination of grain. J. Econ. Entomology 85(4): 1463-1470.

Ridgway, C., and J. Chambers. 1996. Detection of external and internal insect infestation in wheat by near-infrared reflectance spectroscopy. J. Sci. Food Agric. 71(2): 251-264.

Ridgway, C., and J. Chambers. 1998. Detection of insects inside wheat kernels by NIR imaging. J. Near-Infrared Spectroscopy 6(2): 115-119.

Ridgway, C., J. Chambers, and I. A. Cowe. 1999. Detection of grain weevils inside single wheat kernels by a very near infrared two-wavelength model. J. Near-Infrared Spectroscopy 7(4): 213-221.

Ridgway, C., R. Davies, and J. Chambers. 2001. Imaging for the high-speed detection of pest insects and other contaminants in cereal grain in transit. ASAE Paper No. 013056. St. Joseph, Mich.: ASAE.

Schatzki, T. F., and T. A. Fine. 1988. Analysis of radiograms of wheat kernels for quality control. Cereal Chemistry 65(3): 233-239.

Schatzki, T. F., E. K. Wilson, G. B. Kitto, P. Behrens, and I. Heller. 1993. Determination of hidden Sitophilus granarius (Coleoptera: Curculionidae) in wheat by Myosin ELISA. $J$. Econ. Entomology 86(5): 1584-1589. 
Shenk, J. S., J. J. Workman Jr., and M. O. Westerhaus. 1992. Application of NIR spectroscopy to agricultural products. In Handbook of Near-Infrared Analysis, 383-431. D. A. Burns and E. M. Ciurczak, eds. New York, N.Y.: Marcel Dekker.

Shuman, D., J. A. Coffelt, K. W. Vick, and R. W. Mankin. 1993. Quantitative acoustical detection of larvae feeding inside kernels of grain. J. Econ. Entomology 86(3): 933-938.

Storey, C. L., D. B. Sauer, O. Ecker, and D. W. Fulk. 1982. Insect infestations in wheat and corn exported from the United States. J. Econ. Entomology 76(6): 1323-1330.

Throne, J. E. 1994. Life history of immature maize weevils (Coleoptera: Curculionidae) on corn stored at constant temperatures and relative humidities in the laboratory. Environ. Entomology 23(6): 1459-1471.
Trauba, R. L., L. Glaze, E. D. McGary, W. D. Palmer, J. T. Quaife, J. Strozier, and A. Whiteman. 1981. Determination of internal insect infestation of wheat: Collaborative study. J. AOAC 64(6): 1408-1410.

USDA. 1997. Chapter 13: Wheat. In Grain Inspection Handbook, Book II. Washington, D.C.: USDA Grain Inspection, Packers, and Stockyards Administration, Federal Grain Inspection Service. Available at: www.usda.gov/gipsa/reference-library/handbooks/grain-insp/gr book2/bk2ch13.pdf. Accessed on 12 March 2002.

Zayas, I., and P. W. Flinn. 1998. Detection of insects in bulk wheat samples with machine vision. Trans. ASAE 41(3): 883-888. 